\title{
Excellent short- and long-term outcomes after concomitant aortic valve replacement and coronary artery bypass grafting performed by surgeons in training
}

\author{
Akshat Saxena, BMedSci, ${ }^{a}$ Diem Dinh, BSc, PhD, ${ }^{\mathrm{b}}$ Julian A. Smith, MBBS, MS, FRACS, ${ }^{\mathrm{c}}$ \\ Christopher M. Reid, MSc, PhD, ${ }^{\mathrm{b}}$ Gilbert C. Shardey, MBBS, FRACS,${ }^{\mathrm{d}}$ and \\ Andrew E. Newcomb, MBBS, FRACS ${ }^{\mathrm{a}, \mathrm{e}}$
}

\begin{abstract}
Objective: No previous studies have specifically addressed the effect of training on outcomes after concomitant aortic valve replacement and coronary artery bypass grafting. This study evaluated the early and late outcomes after concomitant aortic valve replacement and coronary artery bypass grafting performed by surgeons in training.
\end{abstract}

\begin{abstract}
Methods: A retrospective analysis of data collected prospectively by the Australian and New Zealand Society of Cardiac and Thoracic Surgeons Cardiac Surgery Database between June 2001 and December 2009 was performed. Concomitant aortic valve replacement and coronary artery bypass grafting was performed in 2540 patients; of these procedures, $290(11.4 \%)$ were by trainees. Patient demographics, intraoperative characteristics, and early morbidity were compared between trainee and staff cases using chi-square analysis and $t$ tests. Multivariate analyses were used to determine the independent association of training status with 30-day and late mortality.
\end{abstract}

Results: Compared with staff cases, trainee cases were younger (mean age, 73.0 vs 74.2 years; $P=.025$ ) and less likely to present with triple vessel disease $(27.9 \%$ vs $38.3 \%, P=.001)$ or previous cardiac surgery $(6.3 \%$ vs $2.8 \%, P=.016)$. Trainee cases had longer mean perfusion ( 160.4 vs 144.6 minutes, $P<.001)$ and crossclamp (125.2 vs 114.6 minutes, $P<.001)$ times. The incidence of early complications was similar between the 2 groups. On multivariate analysis, trainee status was not associated with an increased risk of 30-day mortality $(2.4 \%$ vs $4.0 \%, P=.348)$. Moreover, there was no significant difference in long-term outcomes, and 5-year survival was comparable in both groups $(79.6 \%$ vs $77.4 \%, P=.200)$.

Conclusions: Concomitant aortic valve replacement and coronary artery bypass grafting can be safely and effectively performed by properly supervised trainees in the contemporary era. It is imperative to offer training opportunities to junior surgeons in this complex procedure to ensure quality patient outcomes in the future.

(J Thorac Cardiovasc Surg 2013;145:334-40)

Outcomes after cardiac surgery performed by surgeons in training have come under increased scrutiny in the last 2 decades. Concerns have been raised that both the quantity and the quality of training opportunities available to residents have recently deteriorated. ${ }^{1}$ Numerous factors have been

From the Department of Cardiothoracic Surgery, ${ }^{a}$ St Vincent's Hospital Melbourne, Fitzroy; Department of Epidemiology and Preventative Medicine, ${ }^{\mathrm{b}}$ Monash University, Prahran; Department of Surgery (MMC), ${ }^{\mathrm{c}}$ Monash University and Department of Cardiothoracic Surgery, Monash Medical Centre, Clayton; Cabrini Medical Centre, ${ }^{\mathrm{d}}$ Malvern; and University of Melbourne Department of Surgery, St Vincent's Hospital Melbourne, Fitzroy, Victoria, Australia.

The Australian and New Zealand Society of Cardiac and Thoracic Surgeons National Cardiac Surgery Database is funded by the Department of Human Services, Victoria, and the Health Administration Corporation and the Clinical Excellence Commission, NSW.

Disclosures: Authors have nothing to disclose with regard to commercial support.

Received for publication Feb 20, 2012; revisions received Aug 14, 2012; accepted for publication Sept 27, 2012; available ahead of print Oct 29, 2012.

Address for reprints: Andrew E. Newcomb, MBBS, FRACS, Department of Cardiothoracic Surgery, Vincent's Hospital Melbourne, 41 Victoria Parade, Fitzroy, 3065

Victoria, Australia (E-mail: andrew.newcomb@svhm.org.au). $0022-5223 / \$ 36.00$

Crown Copyright (C) 2013 Published by Elsevier Inc. on behalf of The American Association for Thoracic Surgery

http://dx.doi.org/10.1016/j.jtcvs.2012.09.073 implicated. First, the increase in database participation and public reporting of outcomes has increased scrutiny on the performance of individual cardiac surgeons. ${ }^{2}$ This may have translated into a general reluctance in offering training opportunities to junior surgeons. Second, in many countries, legislation-enforced restrictions on working hours have reduced clinical exposure for trainees. ${ }^{3}$ Third, cardiac surgeons are increasingly operating on a more complex patient cohort. This reflects the increased use of percutaneous technologies and the aging populations of Western countries. Increased case complexity also is likely to decrease the training opportunities available to junior surgeons.

Nevertheless, there is a substantial body of evidence suggesting that trainees can both safely and effectively perform cardiac surgery. ${ }^{4-15}$ In fact, numerous studies have shown that early and late outcomes are equivalent regardless of whether a staff or trainee surgeon is the primary operator. Currently, however, the majority of published series have analyzed the impact of training status in the context of isolated coronary artery bypass grafting (CABG) or cardiac surgery in general. Compared with isolated CABG or 


\section{Abbreviations and Acronyms \\ ANZSCTS $=$ Australian and New Zealand Society of Cardiac and Thoracic Surgeons \\ AVR = aortic valve replacement \\ $\mathrm{CABG}=$ coronary artery bypass grafting \\ euroSCORE $=$ European System for Cardiac \\ Operative Risk Evaluation \\ ICU = intensive care unit}

isolated aortic valve replacement (AVR) surgery, concomitant AVR-CABG is a significantly more complex procedure associated with higher mortality and morbidity. Moreover, although isolated CABG and isolated AVR procedures are being performed less often, concomitant AVR-CABG is increasing in frequency. ${ }^{16}$ Therefore, future cardiac surgeons need to be adept at performing this procedure; however, there is a paucity of data assessing the outcomes after concomitant AVR-CABG performed by surgeons in training. The aim of this study is to use a large, multi-institutional Australian database to evaluate the impact of training status on early and late outcomes after concomitant AVR-CABG.

\section{MATERIALS AND METHODS}

All patients undergoing concomitant AVR and CABG between June 1, 2001, and December 31, 2009, at hospitals in Australia participating in the Australian and New Zealand Society of Cardiac and Thoracic Surgeons (ANZSCTS) Cardiac Surgery Database were included in this study. Patients undergoing concomitant valve surgery or other concurrent cardiac surgical procedures were excluded from this study. All 6 Victorian public hospitals that perform adult cardiac surgery-The Royal Melbourne Hospital, The Alfred Hospital, Monash Medical Centre, The Geelong Hospital, Austin Hospital, and St Vincent's Hospital Melbournewere involved in the prospective data collection during the entire period. In addition, 14 cardiac surgical units from South Australia, New South Wales, and Queensland have entered the database project in the last 30 months of the study period and contributed $42.4 \%$ of the total patient numbers.

The ANZSCTS database contains detailed information on patient demographics, preoperative risk factors, operative details, postoperative hospital course, and morbidity and mortality outcomes. These data were collected prospectively using a standardized dataset and definitions. Data collection and audit methods have been described. ${ }^{17}$ In the State of Victoria, the collection and reporting of public hospital cardiac surgery data are compulsory and mandated by the State Government; thus, it is allinclusive. Data validation has been a major focus since the establishment of the ANZSCTS database. The data are subjected to both local validation and an external data quality audit program, which is performed on site to evaluate the completeness (defined as $<1 \%$ missing data for any variable) and accuracy (97.4\%) of the data held in the combined database. Audit outcomes are used to assist in further development of appropriate standards. The Ethics Committee of each participating hospital had previously approved the use of deidentified patient data contained within the database for research and waived the need for individual patient consent.

In the current study, the preoperative (Table 1) and intraoperative (Table 2) characteristics, early outcomes (Table 3), and long-term survival of patients undergoing operations by trainee surgeons were compared with those undergoing operations by staff (consultant) surgeons.
Trainee surgeries were those in which the trainee performed the entire operation as the primary surgeon or the majority of the critical parts of the operations, such as most of the distal coronary anastomoses. In the former situation, staff surgeon supervision varied depending on the level of training of the trainee surgeon, ranging from the staff surgeon assisting the trainee throughout the surgeries to the staff surgeon being available but not directly present in the operating room. Per our database, trainee surgeons were subdivided into 3 groups. First, senior registrars were trainees who were accepted into the Royal Australasian College of Surgeons training program and who had passed the mandatory board examinations but were still completing formal training time. Second, accredited registrars were trainees who were formally accepted into the Royal Australasian College of Surgeons training program but had not completed the mandatory board examinations. These trainees were in postgraduate years 3 to 8. Overseas fellows had undergone cardiothoracic surgery training in a country other than Australia and were completing their training in Australia. The Royal Australasian College of Surgeons has set the criteria for minimum operative experience in cardiothoracic surgery. They require trainees to assist with $400 \mathrm{CABGs}$ and perform 70 , assist with 80 AVRs and perform 10, assist with 30 mitral valve procedures and perform 5. The total operative experience must be recorded in the trainee logbook, which is assessed every 6 months by the Board of Cardiothoracic Surgery. A more thorough description of minimum operative experience has been provided. $^{18}$

Fifteen early postoperative outcomes were analyzed. These were (1) 30day mortality, defined as death within 30 days of operation; (2) permanent stroke, defined as a new central neurologic deficit persisting for more than 72 hours; (3) transient stroke, defined as a new transient neurologic deficit that resolves completely within 72 hours (transient ischemic attack or reversible ischemic neurologic deficit); (4) postoperative acute myocardial infarction, defined as at least 2 of the following: enzyme level elevation, new cardiac wall motion abnormalities, or new $\mathrm{Q}$ waves on serial electrocardiograms; (5) new renal failure, defined as at least 2 of the following: serum creatinine increased to more than $200 \mu \mathrm{mol} / \mathrm{L}$, doubling or greater increase in creatinine when compared with the preoperative value, or new requirement for dialysis or hemofiltration; (6) prolonged ventilation (>24 hours); (7) multisystem failure, defined as concurrent failure of 2 or more of the cardiac, respiratory, or renal systems for at least 48 hours; (8) red blood cell transfusion; (9) gastrointestinal complications; defined as postoperative occurrence of any gastrointestinal complication; (10) deep sternal infection involving muscle and bone as demonstrated by surgical exploration and one of the following: positive cultures or treatment with antibiotics; (11) pneumonia, defined as positive cultures of sputum or transtracheal aspirate and consistent with clinical findings of pneumonia; (12) septicemia, defined as positive blood cultures supported by at least 2 indices of clinical infection; (13) postoperative atrial fibrillation; (14) return to the operating room for any cause; and (15) return to the operating room for bleeding.

To assess the impact of trainee status on 30-day mortality, logistic regression analysis was used to adjust for 18 preoperative patient variables, with the outcome as the dependent variable (variables in Table 4). For other early outcomes, a univariate analysis was performed by using logistic regression and adjusting only for trainee status. Long-term survival status was obtained from the Australian National Death Index. The closing date was March 18, 2010. A Kaplan-Meier estimate of survival was obtained. Differences in long-term survival were assessed by the log-rank test. The role of sex in long-term survival was assessed by constructing a Cox proportional hazards model using sex and other preoperative patient characteristics as variables. Continuous variables are presented as mean \pm 1 standard deviation. The Mann-Whitney $U$ test was used to compare 2 groups of continuous variables. The chi-square test was used to compare groups of categoric variables. All calculated $P$ values were 2 sided. Statistical analysis was performed using the Statistical Package for the Social Sciences for Windows version 17.0 (SPSS Inc, Chicago, Ill). 
TABLE 1. Preoperative characteristics and patient demographics stratified by operator

\begin{tabular}{|c|c|c|c|}
\hline Preoperative variables & Staff cases & Trainee cases & $P$ \\
\hline Total no. of patients $(\%)$ & 2250 & 290 & - \\
\hline Age $($ mean $\pm \mathrm{SD})$ & 74.20 y $(8.3)$ & 73.04 y (7.8) & .02 \\
\hline Female $(\%)$ & $713(31.7)$ & $93(32.1)$ & .89 \\
\hline $\begin{array}{l}\text { Chronic obstructive pulmonary } \\
\text { disease }(\%)\end{array}$ & $413(18.4)$ & $46(15.9)$ & \\
\hline Diabetes mellitus (\%) & $686(30.5)$ & $103(35.5)$ & \\
\hline Hypercholesterolemia (\%) & $1597(71.0)$ & $204(70.3)$ & .8 \\
\hline Hypertension (\%) & $1797(80.0)$ & $234(80.7)$ & \\
\hline Cerebrovascular disease $(\%)$ & $407(18.1)$ & $45(15.5)$ & .78 \\
\hline Peripheral vascular disease $(\%)$ & $352(15.6)$ & $41(14.1)$ & \\
\hline Renal failure $(\%)$ & $97(4.3)$ & $10(3.4)$ & .49 \\
\hline Previous cardiac surgery $(\%)$ & $142(6.3)$ & $8(2.8)$ & .0 \\
\hline $\begin{array}{l}\text { Previous myocardial } \\
\text { infarction }(\%)\end{array}$ & $715(31.8)$ & $83(28.6)$ & \\
\hline $\begin{array}{l}\text { History of congestive heart } \\
\text { failure }(\%)\end{array}$ & $803(35.7)$ & $110(37.9)$ & \\
\hline Triple vessel disease $(\%)$ & $861(38.3)$ & $81(27.9)$ & \\
\hline LVEF & - & - & .13 \\
\hline Normal $(E F>0.60)(\%)$ & $1202(53.4)$ & $169(58.3)$ & - \\
\hline Mild $(E F>0.45)(\%)$ & $550(24.4)$ & $76(26.2)$ & - \\
\hline Moderate (EF 0.30-0.45) (\%) & $310(13.8)$ & $32(11.0)$ & - \\
\hline Severe $(E F<0.30)(\%)$ & $133(5.9)$ & $10(3.4)$ & - \\
\hline Obesity $(\%)$ & $708(31.5)$ & $100(34.5)$ & .29 \\
\hline NYHA classification & - & - & .78 \\
\hline Class I (\%) & $398(17.7)$ & $47(16.2)$ & - \\
\hline Class II $(\%)$ & $808(35.9)$ & $96(33.1)$ & - \\
\hline Class III ( $\%)$ & $824(36.6)$ & $112(38.6)$ & - \\
\hline Class IV (\%) & $182(8.1)$ & $24(8.3)$ & - \\
\hline Status & - & - & .92 \\
\hline Elective $(\%)$ & $1682(74.8)$ & $216(74.5)$ & - \\
\hline Urgent/emergency/salvage $(\%)$ & $568(25.2)$ & $74(25.5)$ & - \\
\hline Critical preoperative state $(\%)$ & $129(5.7)$ & $13(4.5)$ & \\
\hline euroSCORE (additive) & $10.03(3.09)$ & $9.39(2.89)$ & .0 \\
\hline
\end{tabular}

$S D$, Standard deviation; $L V E F$, left ventricular ejection fraction; $E F$, ejection fraction; NYHA, New York Heart Association; euroSCORE, European System for Cardiac Operative Risk Evaluation.

\section{RESULTS}

Concomitant AVR-CABG was undertaken in 2540 patients; of these, trainees performed $290(11.3 \%)$ surgeries. Of these, 105 were performed by a senior registrar, 91 by an accredited registrar and 94 by an overseas fellow. Preoperative and demographic characteristics of trainee and staff patients are provided in Table 1. The mean European System for Cardiac Operative Risk Evaluation (euroSCORE) was lower for trainee patients compared with staff patients $(9.39 \pm 2.89$ vs $10.03 \pm 3.09, P=.001)$.

Intraoperative data are summarized in Table 2. There were some significant differences in intraoperative variables between the 2 groups. In particular, trainees had longer mean cardiopulmonary bypass $(160.37 \pm 50.31$ minutes vs $144.64 \pm 45.53$ minutes, $P<.001)$ and aortic crossclamp $(125.20 \pm 35.84$ minutes vs $114.58 \pm 39.70$ minutes, $P<.001)$ times.
TABLE 2. Intraoperative characteristics stratified by age

\begin{tabular}{|c|c|c|c|}
\hline Preoperative variables & Staff cases & Trainee cases & $\boldsymbol{P}$ \\
\hline Total no. of patients ( $\%)$ & 2250 & 290 & - \\
\hline $\begin{array}{l}\text { Cardiopulmonary bypass time } \\
\quad(\min )(\text { mean } \pm \text { SD) }\end{array}$ & $144.64(45.53)$ & $160.37(50.31)$ & $<.001$ \\
\hline $\begin{array}{l}\text { Aortic crossclamp time }(\mathrm{min}) \\
\quad(\text { mean } \pm \mathrm{SD})\end{array}$ & $114.58(39.70)$ & $125.20(35.84)$ & $<.001$ \\
\hline $\begin{array}{l}\text { No. of distal anastomoses } \\
\quad(\text { mean } \pm \mathrm{SD})\end{array}$ & $2.25(1.16)$ & $1.89(1.00)$ & $<.001$ \\
\hline Type of prosthesis & - & - & .567 \\
\hline Bioprosthesis & $1819(80.8)$ & $243(83.8)$ & - \\
\hline Mechanical valve & $348(15.5)$ & $41(14.1)$ & - \\
\hline Valve size (mean $\pm \mathrm{SD})$ & $23.00(2.17)$ & $22.86(2.24)$ & .334 \\
\hline
\end{tabular}

Overall 30-day mortality and in-hospital mortality were $3.8 \%$ and $4.2 \%$, respectively. The unadjusted 30 -day mortality rate was $4.0 \%$ in staff patients and $2.4 \%$ in trainee patients.

This difference was not significant on univariate analysis $(P=.184)$. The logistic regression model predicting 30-day mortality is shown in Table 4 and demonstrates that trainee status was not an independent predictor for 30-day mortality $(P=.348)$. The independent association of trainee status with other postoperative outcomes is summarized in Table 3. On univariate analysis, trainee status was not associated with an increased mean postoperative length of stay $(11.84 \pm 11.71$ days vs $11.79 \pm 10.52$ days, $P=.938)$ or intensive care unit (ICU) stay $(62.95 \pm 109.68$ hours vs $66.93 \pm 109.68$ hours, $P=.558$ ).

Long-term survival at $1,3,5$, and 7 years postoperatively was similar in trainee patients compared with staff patients on univariate analysis $(92.3 \%$ vs $92.4 \%, 85.6 \%$ vs $85.3 \%$, $79.6 \%$ vs $77.4 \%, \quad 70.0 \%$ vs $68.0 \%$, respectively) $(P=.815)$ (Figure 1). After adjusting for differences in patient variables, there was no difference in survival outcomes between the 2 groups $(P=.200)$. A Cox regression model predicting late mortality is summarized in Table 5 .

\section{DISCUSSION}

Previous studies have shown that provided adequate supervision, trainee surgeons achieve equivalent early and late outcomes after cardiac surgery as staff surgeons. ${ }^{4-15}$ Unfortunately, the majority of these studies have analyzed trainee outcomes within the context of isolated CABG or cardiac surgery in general. Compared with isolated CABG or AVR, combined AVR-CABG is significantly more risky and associated with greater perioperative complications and early and late mortality. To our knowledge, this is the first study that has specifically evaluated the early and late outcomes of concomitant AVR-CABG performed by surgeons in training.

A comparison of the preoperative and intraoperative characteristics between trainee and staff cases demonstrated 
TABLE 3. Early outcomes stratified by operator

Trainee status

\begin{tabular}{lcccc}
\multicolumn{1}{c}{ Outcome } & Trainee cases & Staff cases & $\boldsymbol{P}$ & Unadjusted odds ratio (95\% CI) \\
\hline Permanent stroke (\%) & $48(2.1)$ & $10(3.4)$ & .164 & $1.64(0.82-3.27)$ \\
Transient stroke (\%) & $21(0.9)$ & $1(0.3)$ & .328 & $0.37(0.05-2.73)$ \\
Postoperative myocardial infarction (\%) & $21(0.9)$ & $3(1.0)$ & .870 & $1.11(0.33-3.74)$ \\
New renal failure (\%) & $199(8.8)$ & $25(8.6)$ & .891 & $0.97(0.63-1.50)$ \\
Deep sternal wound infection (\%) & $25(1.1)$ & $4(1.4)$ & .689 & $1.24(0.43-3.59)$ \\
Septicemia (\%) & $43(1.9)$ & $4(1.4)$ & .526 & $0.72(0.26-2.01)$ \\
Pneumonia (\%) & $145(6.4)$ & $16(5.5)$ & .536 & $0.85(0.50-1.44)$ \\
Multisystem failure (\%) & $54(2.4)$ & $6(2.1)$ & .723 & $0.86(0.37-2.01)$ \\
Prolonged ventilation (>24 h) (\%) & $341(15.2)$ & $44(15.2)$ & .994 & $1.00(0.71-1.40)$ \\
Red blood cell transfusion (\%) & $1336(59.4)$ & $182(62.8)$ & .292 & $1.15(0.89-1.47)$ \\
Gastrointestinal complications (\%) & $47(2.1)$ & $11(3.8)$ & .073 & $1.84(0.95-3.60)$ \\
Return to operating room (\%) & $196(8.7)$ & $27(9.3)$ & .743 & $1.07(0.70-1.64)$ \\
Return to operating room for bleeding (\%) & $88(3.9)$ & $13(4.5)$ & .639 & $1.15(0.64-2.09)$ \\
Postoperative atrial fibrillation (\%) & $893(40.0)$ & $123(42.4)$ & .373 & $1.12(0.87-1.43)$ \\
\hline
\end{tabular}

CI, Confidence interval.

some differences. In general, trainees performed operations in younger patients (mean age, 73.0 vs 74.2 years; $P=.025$ ) who were less likely to have undergone previous cardiac surgery $(27.9 \%$ vs $38.3 \%, P<.001)$. This likely reflects the reluctance of senior surgeons to allow trainees to operate on older, sicker patients given the greater risk in this cohort. ${ }^{6,10,14}$ However, there was no difference in the prevalence of other comorbidities, such as renal failure, hypertension, impaired ejection fraction, or critical preoperative state, between the 2 groups. Overall, staff cases had a slightly worse preoperative risk profile with a mean euroSCORE of 10.0 compared with 9.4 for trainees $(P=.001)$. Intraoperatively, trainee cases had higher cardiopulmonary bypass and aortic crossclamp times compared with staff cases. This is an expected finding that has been reported. ${ }^{6,19}$ It reaffirms that, independent of outcomes, an increased operative time is an invariable consequence of surgical training, which should be taken into account in treatment planning.

An analysis of early outcomes demonstrated excellent outcomes in the trainee group. In fact, trainee cases were observed to have a lower operative mortality than staff cases $(2.4 \%$ vs $4.0 \%)$, although this did not reach statistical significance $(P=.348)$. This is an important finding given that few data have demonstrated that AVR-CABG can be safely performed by trainees. Similar findings have been reported for other cardiac surgery procedures. In an analysis of 1054 trainee-performed procedures including 101 patients who

TABLE 4. Predictors for 30-day mortality

\begin{tabular}{|c|c|c|c|c|}
\hline \multirow[b]{2}{*}{ Preoperative variables } & \multicolumn{2}{|c|}{ Univariate analysis } & \multicolumn{2}{|c|}{ Multivariate analysis } \\
\hline & Odds ratio $(95 \% \mathrm{CI})$ & $P$ value & Odds ratio $(95 \% \mathrm{CI})$ & $P$ value \\
\hline Age (mean $\pm \mathrm{SD})$ & $1.06(1.03-1.09)$ & $<.001$ & $1.04(1.01-1.08)$ & .009 \\
\hline Trainee cases & $0.59(0.27-1.29)$ & .189 & $0.68(0.31-1.51)$ & .348 \\
\hline Female & $1.47(0.97-2.22)$ & .070 & $1.37(0.87-2.16)$ & .172 \\
\hline Chronic obstructive pulmonary disease & $1.18(0.72-1.96)$ & .511 & $1.02(0.60-1.71)$ & .951 \\
\hline Diabetes mellitus & $0.94(0.60-1.46)$ & .782 & $0.85(0.52-1.39)$ & .515 \\
\hline Hypercholesterolemia & $0.96(0.61-1.49)$ & .838 & $0.95(0.59-1.54)$ & .836 \\
\hline Hypertension & $1.09(0.65-1.84)$ & .737 & $1.01(0.57-1.77)$ & .983 \\
\hline Cerebrovascular disease & $2.04(1.30-3.19)$ & .002 & $1.62(1.01-2.61)$ & .047 \\
\hline Peripheral vascular disease & $2.18(1.38-3.55)$ & .001 & $1.54(0.93-2.55)$ & .092 \\
\hline Renal failure & $2.12(1.00-4.49)$ & .050 & $1.39(0.57-3.42)$ & .471 \\
\hline Critical preoperative state & $1.45(1.19-1.76)$ & $<.001$ & $1.83(0.79-4.23)$ & .158 \\
\hline Triple vessel disease & $1.56(1.04-2.34)$ & .033 & $1.46(0.94-2.25)$ & .090 \\
\hline Obesity & $0.70(0.44-1.11)$ & .128 & $0.93(0.56-1.54)$ & .775 \\
\hline Recent myocardial infarction & $1.23(0.92-1.64)$ & .166 & $0.89(0.45-1.74)$ & .724 \\
\hline History of congestive heart failure $(\%)$ & $2.11(1.40-3.17)$ & $<.001$ & $1.28(0.81-2.03)$ & .298 \\
\hline $\mathrm{LVEF}<0.45$ & $1.86(1.19-2.91)$ & .007 & $1.23(0.75-2.03)$ & .415 \\
\hline NYHA classification III or IV & $2.85(1.83-4.44)$ & $<.001$ & $2.37(1.46-3.84)$ & .001 \\
\hline Emergency procedure & $2.43(1.61-3.66)$ & $<.001$ & $1.98(0.64-6.09)$ & .236 \\
\hline
\end{tabular}

$C I$, Confidence interval; $S D$, standard deviation; $L V E F$, left ventricular ejection fraction; NYHA, New York Heart Association. 


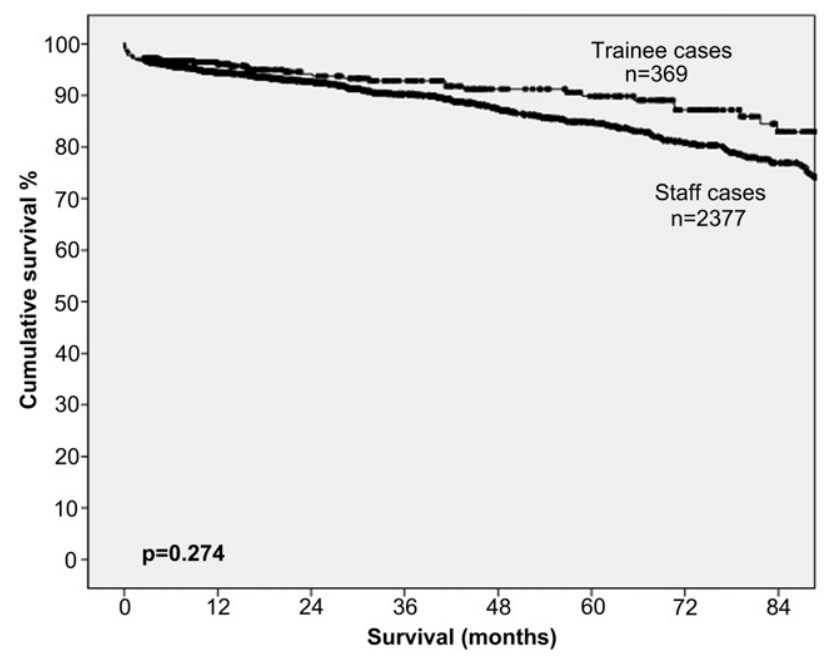

FIGURE 1. Overall survival of patients after concomitant aortic valve replacement and coronary artery bypass grafting, stratified by operator.

underwent AVR-CABG, Stoica and colleagues ${ }^{13}$ did not show an increased in-hospital mortality rate in trainees $(P=.66)$. In an analysis of 555 trainee-performed isolated CABG procedures, Oo and colleagues ${ }^{14}$ actually showed a lower in-hospital mortality for trainee procedures on univariate analysis $(0.9 \%$ vs $2.4 \%, P=.023)$, although there was no difference on multivariate analysis $(P=.36)$. In a series of 584 patients undergoing AVR with or without CABG, Baskett and colleagues ${ }^{7}$ showed no difference in early mortality between the resident and the staff groups $(2.5 \%$ vs $2.9 \%, P=.19)$. The fact that residents can safely perform both off-pump CABG and mitral valve surgery also has been demonstrated. ${ }^{11,12,15}$
Consistent with the findings of other studies, ${ }^{6,11,13-15}$ the current study shows that training status did not increase the likelihood of other early complications. In particular, there was no difference in the incidence of stroke, postoperative myocardial infarction, red blood cell transfusion, prolonged ventilation, renal failure, and return to operating room for bleeding. Moreover, trainee status did not increase the risk of prolonged hospital stay or ICU stay. This is an important finding given the association of ICU and hospital stay with resource use and overall cost of hospitalization. To our knowledge, no previous study has specifically evaluated the association of training status with cost after isolated AVR. For isolated CABG, however, resident procedures have not been shown to increase hospitalization costs. In an analysis of 2740 consecutive CABG procedures, $44.4 \%$ of which were performed by trainees, Goodwin and colleagues ${ }^{8}$ showed that trainee status was not associated with an increased length of ICU stay or overall hospital stay. This translated into similar hospital costs for trainee and consultant procedures. The authors concluded that there needs to be little conflict between service and training needs, even in hospitals with extensive training programs. Although we are unable to quantify the cost of surgery for AVR with the current database, our findings are encouraging. Nevertheless, a dedicated comparison of cost of surgery between trainee and staff surgeons is essential to determine whether training status increases the cost of treatment.

Long-term survival was not different between the 2 groups. Unadjusted 5-year survival was $77.4 \%$ and $79.6 \%$ in trainee and staff cases, respectively. After confounding factors were accounted for in the multivariate

TABLE 5. Predictors for late mortality

\begin{tabular}{|c|c|c|c|c|}
\hline \multirow{2}{*}{$\begin{array}{c}\text { Preoperative variables } \\
\text { Late mortality }\end{array}$} & \multicolumn{2}{|c|}{ Univariate analysis } & \multicolumn{2}{|c|}{ Multivariate analysis } \\
\hline & Odds ratio $(95 \% \mathrm{CI})$ & $P$ value & Odds ratio $(95 \% \mathrm{CI})$ & $P$ value \\
\hline Age $($ mean $\pm \mathrm{SD})$ & $1.05(1.04-1.07)$ & $<.001$ & $1.05(1.03-1.06)$ & $<.001$ \\
\hline Trainee cases & $1.03(0.78-1.37)$ & .815 & $1.21(0.91-1.61)$ & .200 \\
\hline Female & $1.10(0.90-1.34)$ & .361 & $1.14(0.92-1.42)$ & .222 \\
\hline Chronic obstructive pulmonary disease & $1.41(1.13-1.77)$ & .002 & $1.39(1.10-1.75)$ & .005 \\
\hline Diabetes mellitus & $1.12(0.92-1.37)$ & .276 & $1.12(0.90-1.39)$ & .320 \\
\hline Hypercholesterolemia & $0.86(0.70-1.05)$ & .146 & $0.84(0.68-1.04)$ & .113 \\
\hline Hypertension & $0.96(0.76-1.20)$ & .699 & $0.92(0.72-1.17)$ & .472 \\
\hline Cerebrovascular disease & $1.59(1.28-1.99)$ & $<.001$ & $1.27(1.00-1.61)$ & .049 \\
\hline Peripheral vascular disease & $1.68(1.34-2.10)$ & $<.001$ & $1.37(1.08-1.74)$ & .010 \\
\hline Renal failure & $2.63(1.87-3.71)$ & $<.001$ & $1.68(1.11-2.56)$ & .015 \\
\hline Critical preoperative state & $1.41(1.29-1.55)$ & $<.001$ & $1.75(1.21-2.55)$ & .003 \\
\hline Triple vessel disease & $1.46(1.21-1.76)$ & $<.001$ & $1.28(1.05-1.57)$ & .016 \\
\hline Obesity & $0.74(0.59-0.92)$ & .006 & $0.87(0.69-1.10)$ & .238 \\
\hline Recent myocardial infarction & $1.37(1.21-1.57)$ & $<.001$ & $1.30(0.96-1.76)$ & .090 \\
\hline History of congestive heart failure $(\%)$ & $1.80(1.49-2.17)$ & $<.001$ & $1.39(1.13-1.72)$ & .002 \\
\hline LVEF $<0.45$ & $1.89(1.54-2.32)$ & $<.001$ & $1.43(1.14-1.80)$ & .002 \\
\hline NYHA classification III or IV & $1.37(1.13-1.66)$ & .001 & $0.99(0.80-1.22)$ & .926 \\
\hline Emergency procedure & $1.63(1.34-1.98)$ & $<.001$ & $1.13(0.62-2.06)$ & .681 \\
\hline
\end{tabular}

$C I$, Confidence interval; $S D$, standard deviation; $L V E F$, left ventricular ejection fraction; $N Y H A$, New York Heart Association. 
analysis, trainee status was not associated with worse longterm outcomes (hazard ratio, 1.2; 95\% confidence interval, $0.91-1.61 ; P=.200$ ). Compared with early mortality, there is a paucity of data documenting the long-term survival outcomes after AVR-CABG performed by surgeons in training. We have recently demonstrated that training status is not associated with an increased risk of late mortality after mitral valve surgery. ${ }^{15}$ Other studies have demonstrated that excellent long-term outcomes can be expected after residentperformed CABG. ${ }^{6,13,14}$ Oo and colleagues ${ }^{14}$ showed an equivalent 4-year survival in trainee and nontrainee cases at $93.3 \%$ and $90.3 \%$, respectively $(P=.53)$. Stoica and colleagues ${ }^{13}$ demonstrated a similar 5 -year event-free survival in consultant and trainee general cardiac surgery procedures at $58.6 \%$ and $55.8 \%$, respectively $(P=.42)$. Similar results were observed when only patients who underwent AVR (with or without CABG) were considered $(P=.46)$. The general consensus in the literature is that training status does not compromise long-term outcomes after cardiac surgery. Our results support these findings.

The current study has several advantages and disadvantages. The main advantage is that it is a large, contemporary, multi-institutional analysis that is likely to reflect realworld practice reasonably accurately. The main disadvantage is that it is a retrospective study. As such, confounding due to unrecognized factors is likely. Moreover, selection bias is likely to be present given that trainee and staff surgeons generally allocated the cases that trainees were to perform. Higher-risk cases or more technically demanding cases will have been selectively performed by the consultants, and this is reflected in the higher mean euroSCORE. Another limitation of this study is that we did not treat the allocation of surgeries on an intent-to-treat basis. As such, when a consultant surgeon completed a surgery initiated by a trainee, it was almost invariably regarded as a consultant case. Further to this, our database does not allow us to determine which procedures were performed with the staff specialist in the operating room or not. This is an important limitation given that the incidence of some postoperative complications, in particular reoperation for bleeding and deep sternal wound infection, may have been affected by the absence of the staff specialist in the operating room. This limitation, however, is not only confined to our study. Other important studies that have evaluated the role of training status on outcomes across a spectrum of cardiac surgery procedure were not able to determine whether the presence or absence of a staff specialist surgeon in the operating room affected outcomes. ${ }^{6,7,10,12-15}$ Finally, we are unable to comment on the seniority of each individual trainee, a factor that might make a difference.

\section{CONCLUSIONS}

Our study demonstrates that trainee surgeons can safely and effectively perform concomitant AVR-CABG. This is a significant finding given the paucity of data assessing the impact on trainee status on outcomes after AVRCABG. These data are encouraging and suggest that the reluctance in allowing trainees to perform this complex procedure needs to be reevaluated. Nevertheless, further studies are necessary to validate our data.

The following investigators, data managers, and institutions participated in the ANZSCTS Database: Alfred Hospital: A. Pick, J. Duncan; Austin Hospital: S. Seevanayagam, M. Shaw; Cabrini Health: G. Shardey; Geelong Hospital: M. Morteza, C. Bright; Flinders Medical Centre: J. Knight, R. Baker, J. Helm; Jessie McPherson Private Hospital: J. Smith, H. Baxter; Hospital: John Hunter Hospital: A. James, S. Scaybrook; Lake Macquarie Hospital: B. Dennett, M. Jacobi; Liverpool Hospital: B. French, N. Hewitt; Mater Health Service Hospital: A. M. Diqer, J. Archer; Monash Medical Centre: J. Smith, H. Baxter; Prince of Wales Hospital: H. Wolfenden, D. Weerasinge; Royal Melbourne Hospital: P. Skillington, S. Law; Royal Prince Alfred Hospital: M. Wilson, L. Turner; St George Hospital: G. Fermanis, C. Redmond; St Vincent's Hospital, VIC: M. Yii, A. Newcomb, J. Mack, K. Duve; St Vincent's Hospital, NSW: P. Spratt, T. Hunter; The Canberra Hospital: P. Bissaker, K. Butler; Townsville Hospital: R. Tam, A. Farley; Westmead Hospital: R. Costa, M. Halaka.

\section{References}

1. Crofts TJ, Griffiths JM, Sharma S, Wygrala J, Aitken RJ. Surgical training: an objective assessment of recent changes for a single health board. BMJ. 1997; 314:891-5.

2. Keogh B, Spiegelhalter D, Bailey A, Roxburgh J, Magee P, Hilton C. The legacy of Bristol: public disclosure of individual surgeons' results. BMJ. 2004;329: 450-4.

3. Lim E, Tsui S. Impact of the European Working Time Directive on exposure to operative cardiac surgical training. Eur J Cardiothorac Surg. 2006;30:574-7.

4. Sethi GK, Hammermeister KE, Oprian C, Henderson W. Impact of resident training on postoperative morbidity in patients undergoing single valve replacement Department of Veterans Affairs Cooperative Study on Valvular Heart Disease. J Thorac Cardiovasc Surg. 1991;101:1053-9.

5. Ascione R, Reeves BC, Pano M, Angelini GD. Trainees operating on high-risk patients without cardiopulmonary bypass: a high-risk strategy? Ann Thorac Surg. 2004;78:26-33

6. Yap CH, Andrianopoulos N, Dinh TD, Billah B, Rosalion A, Smith JA, et al. Short- and midterm outcomes of coronary artery bypass surgery performed by surgeons in training. J Thorac Cardiovasc Surg. 2009;137:1088-92.

7. Baskett RJ, Buth KJ, Legare JF, Hassan A, Hancock Friesen C, Hirsch GM, et al Is it safe to train residents to perform cardiac surgery? Ann Thorac Surg. 2002;74 1043-9.

8. Goodwin AT, Birdi I, Ramesh TP, Taylor GJ, Nashef SA, Dunning JJ, et al. Effect of surgical training on outcome and hospital costs in coronary surgery. Heart 2001;85:454-7.

9. Gulbins H, Pritisanac A, Ennker IC, Ennker J. Safety of a cardiac surgical training program over a twelve-year period. Thorac Cardiovasc Surg. 2007;55:494-9.

10. Asimakopoulos G, Karagounis AP, Valencia O, Rose D, Niranjan G, Chandrasekaran V. How safe is it to train residents to perform off-pump coronary artery bypass surgery? Ann Thorac Surg. 2006;81:568-72.

11. Karagounis A, Asimakopoulos G, Niranjan G, Valencia O, Chandrasekaran V. Complex off-pump coronary artery bypass surgery can be safely taught to cardiothoracic trainees. Interact Cardiovasc Thorac Surg. 2006;5:222-6.

12. Baskett RJ, Kalavrouziotis D, Buth KJ, Hirsch GM, Sullivan JA. Training residents in mitral valve surgery. Ann Thorac Surg. 2004;78:1236-40.

13. Stoica SC, Kalavrouziotis D, Martin BJ, Buth KJ, Hirsch GM, Sullivan JA, et al. Long-term results of heart operations performed by surgeons-in-training. Circulation. 2008;118(14 Suppl):S1-6.

14. Oo AY, Grayson AD, Rashid A. Effect of training on outcomes following coronary artery bypass graft surgery. Eur J Cardiothorac Surg. 2004;25:591-6. 
15. Shi WY, Hayward PA, Yap CH, Dinh DT, Reid CM, Shardey GC, et al. Training in mitral valve surgery need not affect early outcomes and midterm survival: a multicentre analysis. Eur J Cardiothorac Surg. 2011;40: 826-33.

16. Shahian DM, Edwards FH. The Society of Thoracic Surgeons 2008 cardiac surgery risk models: introduction. Ann Thorac Surg. 2009;88(1 Suppl):S1.

17. Dinh DT, Lee GA, Billah B, Smith JA, Shardey GC, Reid CM. Trends in coronary artery bypass graft surgery in Victoria, 2001-2006: findings from the Australasian
Society of Cardiac and Thoracic Surgeons database project. Med J Aust. 2008; 188:214-7.

18. Surgeons RACo. Criteria for Minimum Operative Experience. Available at: http://www.surgeons.org/surgical-specialties/cardiothoracic/criteria-for-minimaloperative-experience/. Accessed August 8, 2012.

19. Haan CK, Milford-Beland S, O'Brien S, Mark D, Dullum M, Ferguson TB, et al. Impact of residency status on perfusion times and outcomes for coronary artery bypass graft surgery. Ann Thorac Surg. 2007;83:2103-10.

Access to The Journal of Thoracic and Cardiovascular Surgery Online is reserved for print subscribers!

Full-text access to The Journal of Thoracic and Cardiovascular Surgery Online is available for all print subscribers. To activate your individual online subscription, please visit The Journal of Thoracic and Cardiovascular Surgery Online, point your browser to http://www.mosby.com/jtcvs, follow the prompts to activate your online access, and follow the instructions. To activate your account, you will need your subscriber account number, which you can find on your mailing label (note: the number of digits in your subscriber account number varies from 6 to 10). See the example below in which the subscriber account number has been circled:

\section{Sample mailing label}

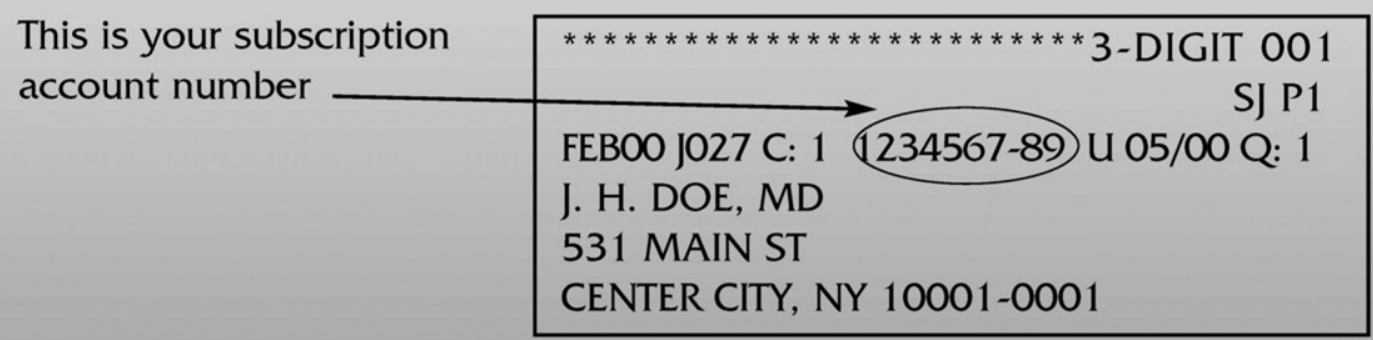

Personal subscriptions to The Journal of Thoracic and Cardiovascular Surgery Online are for individual use only and may not be transferred. Use of The Journal of Thoracic and Cardiovascular Surgery Online is subject to agreement to the terms and conditions as indicated online. 